\title{
Coronavirus Disease-19 Pneumonia with Facial Nerve Palsy and Olfactory Disturbance
}

\author{
Yoshito Homma $^{1}$, Masashi Watanabe ${ }^{2}$, Koji Inoue ${ }^{1}$ and Tomonori Moritaka ${ }^{1}$
}

\begin{abstract}
:
The novel coronavirus disease-2019 (COVID-19), caused by severe acute respiratory syndrome coronavirus-2, has spread worldwide from China. There are no case reports from Asia of COVID-19 with facial paralysis and olfactory disturbance. We herein report a case of COVID-19 pneumonia in a Japanese woman who showed facial nerve palsy and olfactory disturbance.
\end{abstract}

Key words: severe acute respiratory syndrome coronavirus-2, COVID-19, facial nerve palsy, olfactory disturbance, multiple peripheral neuropathies, Kampo

(Intern Med 59: 1773-1775, 2020)

(DOI: 10.2169/internalmedicine.5014-20)

\section{Introduction}

Severe acute respiratory syndrome coronavirus-2 (SARSCoV-2) is similar to SARS-CoV and is classified as a betacoronavirus. Beginning in December 2019, a novel infectious disease caused by SARS-CoV-2 (COVID-19) spread worldwide from China (1). As of April 2, more than 850,000 patients have been infected worldwide (2)-at the time of writing there is no sign of an end to the pandemic. According to a report from China, the overall mortality rate of COVID-19 is $2.3 \%$. The mortality rate in those under 50 years of age is low. However, the disease is more severe in the elderly and in patients with underlying diseases such as hypertension and heart conditions. The main symptoms of COVID-19 are fever and cough. If the disease progresses to pneumonia or acute respiratory distress syndrome (ARDS), dyspnea can develop. Digestive symptoms are rare, and neurological symptoms have not been reported from China (3-6). A Japanese woman who returned from Italy developed COVID-19. She had pneumonia and multiple cranial neuropathies of the right face and tongue. According to media reports or academic statements, COVID-19 often causes olfactory and taste disorder. However, there has, to our knowledge, been no report of multiple peripheral neuropathies. We herein report a case of COVID-19 with facial nerve palsy and olfactory disturbance.

\section{Case Report}

In October 2019, a 35-year-old Japanese woman boarded a cruise ship as an interpreter. The cruise ship returned to Italy in early March 2020 after traveling the Mediterranean coast for almost 5 months. It was reported that an Austrian developed COVID-19 after leaving the ship and returning home. On this basis, the cruise ship staff waited on board for 1 week while being monitored. The patient returned to Japan via Rome shortly after leaving the ship two days before admission. While traveling to Japan, she suffered from cough, malaise, sore throat, and nausea. By the time she returned to Japan, her sore throat had improved. But she experienced fever and malaise, as well as a worsening of her cough on admission day. Rapid tests for influenza and streptococci yielded negative results. Radiographs showed no abnormalities, but computed tomography showed multiple ground-glass opacities in both lungs (Fig. 1). A sample of the nasopharynx was collected based on her history of travel; that sample was positive for SARS-CoV-2 by polymerase chain reaction (PCR). The patient had no abnormal vital signs but was hospitalized according to the Japanese Prevention of Infectious Diseases and Medical Care for Patients with Infectious Diseases Act. On the day of admission, her

${ }^{1}$ Department of Respiratory Medicine, Ehime Prefectural Central Hospital, Japan and ${ }^{2}$ Department of Neurology, Ehime Prefectural Central Hospital, Japan

Received for publication April 3, 2020; Accepted for publication May 11, 2020

Correspondence to Dr. Yoshito Homma, c-yohomma@eph.pref.ehime.jp 


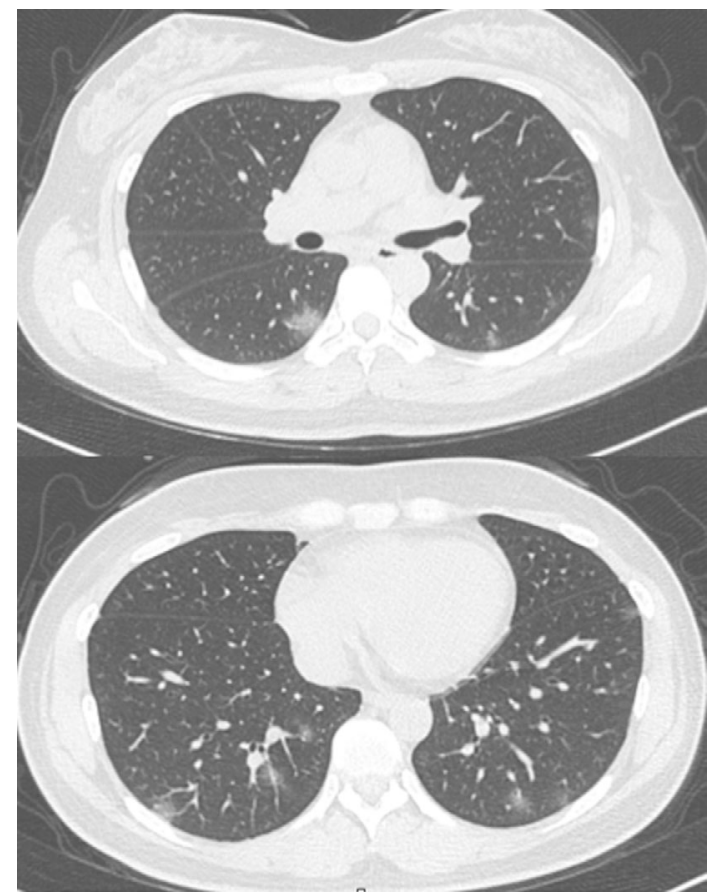

Figure 1. Chest computed tomography detected multiple ground-glass opacities in both lungs.

body temperature was $39.8^{\circ} \mathrm{C}$, pulse rate was $110 / \mathrm{min}$, blood pressure was $112 / 85 \mathrm{mmHg}$, respiratory rate was $18 /$ min, and $\mathrm{SpO}_{2}$ was $99 \%$ (room air). Her consciousness was clear. The patient was experiencing symptoms of fever, headache, cough, and malaise; her sore throat and nausea had resolved. She has no past history but she was a habitual smoker. The physical findings showed no conjunctival congestion and no yellowing, and tenderness in the right neck with swollen tonsils, but no tonsillar exudate or cervical lymphadenopathy. Her respiratory sounds were normal, and her abdomen was soft without tenderness. Neurological findings revealed facial paralysis on the right side of her face (Fig. 2). Her sense of taste on the right side of the tongue was almost completely lost; only a sense of sweetness remained. Her sense of smell completely disappeared, she was unable to smell shampoo, coffee, or soy sauce. There was no neck stiffness or jolt accentuation. Blood tests showed a blood cell count of $3,320 / \mathrm{mL}$ (neutrophils $72 \%$, lymphocytes $18.4 \%$, basophils $0.3 \%$, eosinophils $2.1 \%$, and monocytes $7.2 \%$ ). The patient's hemoglobin value was $14.1 \mathrm{~g} / \mathrm{dL}$ and her platelet count was $262 \times 10^{3} / \mathrm{mL}$, with a peak Creactive protein level of $2.81 \mathrm{mg} / \mathrm{dL}$. Other laboratory parameters were within the normal ranges. The cerebrospinal fluid (CSF) pressure was $20 \mathrm{cmH}_{2} \mathrm{O}$, cell count was $<1 / \mu \mathrm{L}$, total protein was $17 \mathrm{mg} / \mathrm{dL}$, glucose was $61 \mathrm{mg} / \mathrm{dL}$, and a SARS-CoV-2 PCR assay yielded negative results. Based on these findings, the patient was diagnosed with COVID-19 pneumonia associated with facial nerve palsy and olfactory disturbance.

On the day of admission to our hospital, the administration of acetaminophen and the Japanese Kampo medicine Maoto was started. In Japan, Maoto is used for elderly pa-

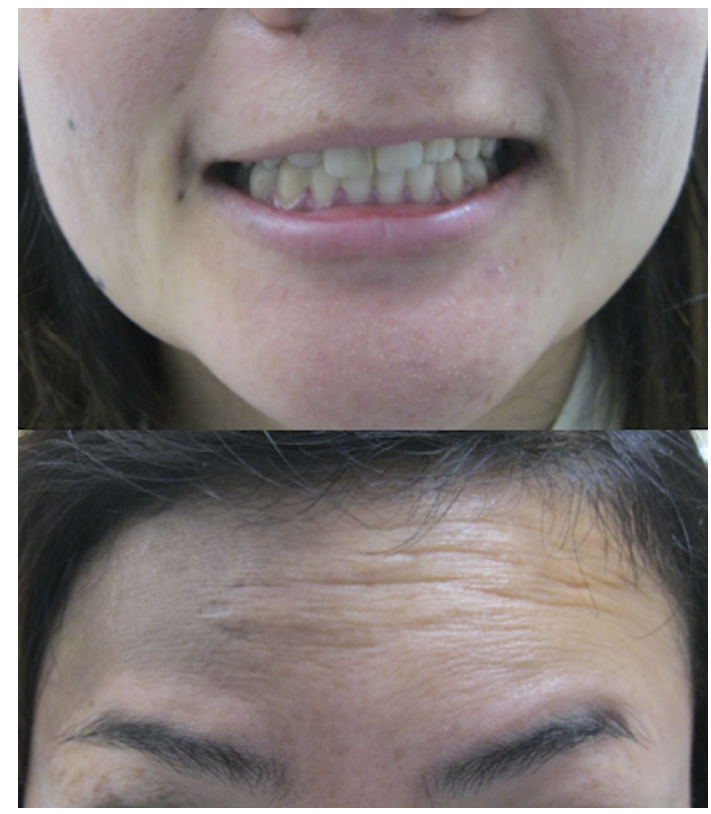

Figure 2. Motor weakness of the right forehead and corner of the mouth.

tients with febrile illnesses such as influenza. In addition, Maoto is occasionally used for acute-phase Bell's paralysis. The patient was not administered antivirals or antibiotics because her vital signs were stable. From two to four days after admission, her fever $\left(37-38^{\circ} \mathrm{C}\right)$ and cough continued, but malaise, facial nerve palsy, and smell and taste disorder were slowly improving. Five days after admission, the patient's oxygenation and respiratory symptoms had worsened. Her body temperature was $38.5^{\circ} \mathrm{C}$, pulse rate was $115 / \mathrm{min}$, respiratory rate was $24 / \mathrm{min}$ and $\mathrm{SpO}_{2}$ was $95 \%$ (room air). Inhalation of ciclesonide was started. Six days after admission, favipiravir was administered. Thereafter her condition did not worsen and her smell and taste disorder and facial paralysis improved completely. Eleven days after admission, fever resolved, and oxygen administration was stopped. Sixteen days after admission, she was discharged after two consecutive samples showed a negative finding for SARS-CoV2 by PCR.

\section{Discussion}

We herein report a case of COVID-19 with mild pneumonia, facial palsy, and olfactory disturbance. The patient's motor function was decreased on the forehead and corner of the mouth on the right side, and her sense of taste on the right side of the tongue was reduced. Bell's palsy is the most common peripheral facial palsy and is believed to be caused by the reactivation of latent herpes simplex virus type 1. Taste disorder is a symptom of Bell's palsy, but olfactory disturbance is not. The patient could not recognize odors, likely because of peripheral neuropathy of the olfactory nerve. The negative results of SARS-CoV-2 PCR and laboratory tests of the CSF ruled out meningitis. We speculated that SARS-CoV-2 was causing multiple peripheral neu- 
ropathies. SARS-CoV-2 has been reported to propagate by binding to angiotensin converting enzyme (ACE2) receptors, which are expressed in the lung, heart, kidney, digestive tract, and brain. SARS-CoV-2 may reach the central nervous system via viremia or through the mucosa of the upper respiratory tract (7). In this case, SARS-CoV-2 likely caused peripheral neuropathy of the facial and olfactory nerves through the upper respiratory tract, because throat pain and cough developed before the onset of pneumonia. There are, to our knowledge, no reports of COVID-19 with facial nerve palsy. A Google search showed that European media had reported the loss of the sense of smell to be a feature of COVID-19, but reports from China did not mention any neurological symptoms (3-6). In addition, neurological symptoms have not been reported in Japan from January to late March in 2020. We speculate that the pathogenicity and symptoms of SARS-CoV-2 may therefore have changed as the virus spread outside Asia.

In this case, we did not use systemic steroids after making a diagnosis of facial palsy. There is no case of facial nerve palsy caused by COVID-19, and we could not exclude Bell's palsy as an alternative diagnosis. The use of steroids for Bell's palsy is strongly recommended (8), but is controversial for COVID-19 because they delay clearance of SARS-CoV-2 (9-11). However, a retrospective observational study in China suggested that patients with ARDS have a lower mortality rate (12). In this case, we administered only medications (acetaminophen and Chinese herbs) to relieve the mild neurological symptoms. If neurological symptoms are severe, the use of steroids should be considered even for COVID-19. Our findings suggest that the decision on whether to administer steroids should be made on a case-bycase basis depending on the severity of the neurological symptoms and pneumonia. Further case reports and studies are needed to determine whether COVID-19 can cause multiple peripheral neuropathies.

SARS-CoV-2 PCR assays were performed at Ehime Prefectural Institute of Public Health and Environmental Science.

The authors state that they have no Conflict of Interest (COI).

\section{References}

1. Zhu N, Zhang D, Wang W, et al. A novel coronavirus from patients with pneumonia in China, 2019. N Engl J Med 382: 727$733,2020$.

2. World Health Organization website [Internet]. [cited 2020 Mar 26]. Available from: https://www.who.int/emergencies/diseases/nov el-coronavirus-2019.

3. Guan WJ, Ni ZY, Hu Y, et al. Clinical characteristics of coronavirus disease 2019 in China. N Engl J Med 382: 1708-1720, 2020.

4. Huang $\mathrm{C}$, Wang $\mathrm{Y}$, Li X, et al. Clinical features of patients infected with 2019 novel coronavirus in Wuhan, China. Lancet 395: 497-506, 2020.

5. Chen N, Zhou M, Dong X, et al. Epidemiological and clinical characteristics of 99 cases of 2019 novel coronavirus pneumonia in Wuhan, China: a descriptive study. Lancet 395: 507-513, 2020.

6. Wang D, Hu B, Hu C, et al. Clinical characteristics of 138 hospitalized patients with 2019 novel coronavirus-infected pneumonia in Wuhan, China. JAMA 323: 1061-1069, 2020.

7. Baig AM, Khaleeq A, Ali U, Syeda H. Evidence of the COVID-19 virus targeting the CNS: tissue distribution, host-virus interaction, and proposed neurotropic mechanisms. ACS Chem Neurosci 11: 995-998, 2020.

8. Baugh RF, Basura GJ, Ishii LE, et al. Clinical practice guideline: Bell's palsy. Otolaryngol Head Neck Surg 149 (3 Suppl): S1-S27, 2013.

9. Russell CD, Millar JE, Baillie JK. Clinical evidence does not support corticosteroid treatment for 2019-nCoV lung injury. Lancet 395: 473, 2020 Epub 2020 Feb 7.

10. Centers for Disease Control and Prevention. Interim Clinical Guidance for Management of Patients with Confirmed 2019 Novel Coronavirus (2019-nCoV) Infection [Internet]. February 12, 2020 [updated 2020 Apr 1; cited 2020 May 1]. Available from: https://w ww.cdc.gov/coronavirus/2019-ncov/hcp/clinical-guidance-managem ent-patients.html.

11. World Health Organization. Novel Coronavirus (2019-nCoV) Technical Guidance: patient management [Internet]. [cited 2020 Mar 26]. Available from: https://www.who.int/emergencies/disease s/novel-coronavirus-2019/technical-guidance/patient-management.

12. Wu C, Chen X, Cai Y, et al. Risk factors associated with acute respiratory distress syndrome and death in patients with coronavirus disease 2019 pneumonia in Wuhan, China. JAMA Intern Med, Forthcoming.

The Internal Medicine is an Open Access journal distributed under the Creative Commons Attribution-NonCommercial-NoDerivatives 4.0 International License. To view the details of this license, please visit (https://creativecommons.org/licenses/ by-nc-nd/4.0/).

(C) 2020 The Japanese Society of Internal Medicine Intern Med 59: 1773-1775, 2020 